\title{
Efficacy and duration of action of the antileukotriene zafirlukast on cold air-induced bronchoconstriction
}

\author{
K. Richter, R.A. Jörres, H. Magnussen
}

\begin{abstract}
Efficacy and duration of action of the antileukotriene zafirlukast on cold air-induced bronchoconstriction. K. Richter, R.A. Jörres, H. Magnussen. (C)ERS Journals Ltd 2000.

ABSTRACT: The objectives of the study were to assess the magnitude of the effect of the leukotriene receptor antagonist, zafirlukast, against cold air-induced bronchoconstriction following the first dose and to assess magnitude and duration after 5 days of dosing.

Nineteen patients with asthma were included. In a randomized cross-over design, either zafirlukast $20 \mathrm{mg}$ or $80 \mathrm{mg}$ b.d. or placebo were given over 5 days. Challenges were performed $3 \mathrm{~h}$ post first dose and $3,8,12$ and $24 \mathrm{~h}$ post last dose. The authors assessed the provocative ventilation rate necessary to achieve a $10 \%(\mathrm{PV} 10)$ and $20 \%$ (PV20) fall in forced expiratory volume in one second.

The median PV20 $3 \mathrm{~h}$ post first dose was $69.1 \mathrm{~L} \cdot \mathrm{min}^{-1}$ for zafirlukast $80 \mathrm{mg}$ compared to $40 \mathrm{~L} \cdot \mathrm{min}^{-1}$ for placebo $(p=0.004)$. The corresponding median value for zafirlukast $20 \mathrm{mg}$ was $59.9 \mathrm{~L} \cdot \mathrm{min}^{-1}(\mathrm{p}=0.06)$. At steady state the differences in PV20, between zafirlukast $80 \mathrm{mg}$ and placebo were significant at $8 \mathrm{~h}$ and $12 \mathrm{~h}$ post last dose. The corresponding difference for zafirlukast $20 \mathrm{mg}$ was statistically significant at $8 \mathrm{~h}$ post last dose. The analysis of PV10 yielded compatible results. There was no significant protection $24 \mathrm{~h}$ after last dose.

This study has demonstrated that zafirlukast offers significant protection against cold air-induced bronchoconstriction in asthma. The degree and duration of protection were dose-dependent. However, there was a large interindividual variability for the protective effect of this leukotriene receptor antagonist.

Eur Respir J 2000; 15: 693-699.
\end{abstract}

Exercise and isocapnic hyperventilation of cold, dry air are similar stimuli causing airway narrowing in asthmatic subjects. Even though there is still an ongoing discussion about the exact mechanism by which exercise or cold air induces asthmatic responses there is substantial evidence that bronchoactive mediators like histamine, prostaglandins and leukotrienes play an important role [1-3]. Antileukotrienes have repeatedly been shown to be effective in attenuating bronchoconstriction induced by exercise [4-8] or hyperventilation of cold air $[9,10]$. As exercise is vance the authors have studied the onset and the duration of the inhibitory effect of antileukotrienes. Recently preliminary reports have shown inconsistent results for the protective effect on cold air induced bronchoconstriction after a single dose of the leukotriene receptor antagonist zafirlukast $[11,12]$.

The authors studied the effect of zafirlukast on airway obstruction induced by hyperventilation of cold air in 19 stable asthmatics. The objectives of the present study were to assess the magnitude of the effect of zafirlukast against cold air-induced bronchoconstriction $(20 \mathrm{mg}$ b.d. and 80 $\mathrm{mg}$ b.d.) compared with placebo $3 \mathrm{~h}$ following the first dose and to assess magnitude and duration of the effect of zafirlukast at steady state conditions after 5 days of dosing. Therefore airway response was assessed at 3, 8, 12 and 24 $\mathrm{h}$ after the last morning dose. a naturally occurring stimulus which is of clinical rele-
Krankenhaus Großhansdorf, Zentrum für Pneumologie und Thoraxchirurgie, Landesversicherungsanstalt Freie und Hansestadt Hamburg, Großhansdorf, Germany.

Correspondence: K. Richter, Krankenhaus Großhansdorf, Zentrum für Pneumologie und Thoraxchirurgie, Freie und Mansestadt Hamburg, Wöhrendamm 80, 22927 Großhansdorf, Germany.

Fax: 494102601379

\section{Keywords: Asthma}

cold air-induced bronchoconstriction

leukotriene receptor antagonist

leukotrienes

zafirlukast

Received: March 41999

Accepted after revision December 71999

This study was supported by Zeneca Pharmaceuticals, Plankstadt, Germany.

\section{Patients}

The approval of an ethical committee (Chamber of physicians, State of Schleswig-Holstein, Germany) was obtained and all subjects gave their informed written consent. Twelve males and 7 females (mean age 30 yrs; range 19-46 yrs) with clinically stable asthma treated with inhaled $\beta_{2}$-agonists alone or with inhaled corticosteroids up to a dose of $1,000 \mu \mathrm{g} \cdot$ day $^{-1}$ and a known history of exerciseinduced asthma were studied (table 1). All patients were nonsmokers (never-smokers or exsmokers who had stopped smoking at least 18 months before the study), mean forced expiratory volume in one second (FEV1) was 92 (range 75-112) \% predicted. Methacholine challenges were performed as described previously [13]. All patients had airway hyperresponsiveness to inhaled methacholine with a provocative concentration causing a $20 \%$ fall in FEV1 (PC20) of $<2.0 \mathrm{mg} \cdot \mathrm{mL}^{-1}$ methacholine. All subjects except one (No. 1) showed a positive skin-prick test to at least one of 20 common allergens. Within six weeks of screening all subjects had a positive cold air challenge. The provocative ventilation rate to reduce FEV1 by $20 \%$ (PV20) was determined by a cold air hyperventilation challenge of 20-60 L. $\mathrm{min}^{-1}$. One subject (No. 6) with a PV20, of $63.3 \mathrm{~L} \cdot \mathrm{min}^{-1}$ was included in the study and the highest ventilation rate for this subject was $70 \mathrm{~L} \cdot \mathrm{min}^{-1}$ 
Table 1. - Patient's characteristics

\begin{tabular}{|c|c|c|c|c|c|c|c|c|c|c|c|}
\hline $\begin{array}{l}\mathrm{Pt} \\
\text { No. }\end{array}$ & $\begin{array}{l}\text { Sex } \\
\mathrm{M} / \mathrm{F}\end{array}$ & $\begin{array}{l}\text { Height } \\
\mathrm{cm}\end{array}$ & $\begin{array}{l}\text { Age } \\
\text { yrs }\end{array}$ & Exsmoker & Allergy & $\begin{array}{c}\mathrm{PC} 20 \\
\mathrm{mg} \cdot \mathrm{mL}^{-1}\end{array}$ & $\begin{array}{c}\mathrm{PV} 20 \\
\mathrm{~L} \cdot \mathrm{min}^{-1}\end{array}$ & $\begin{array}{l}\mathrm{VC} \\
\mathrm{L}\end{array}$ & $\begin{array}{c}\text { FEV1 } \\
\text { L }\end{array}$ & $\begin{array}{l}\text { FEV1 } \\
\% \text { pred }\end{array}$ & Medication \\
\hline 1 & F & 168 & 45 & - & - & 0.26 & 36.1 & 4.12 & 2.56 & 88.0 & B \\
\hline 2 & $\mathrm{M}$ & 185 & 28 & - & + & 0.28 & 44.8 & 5.16 & 4.22 & 90.8 & B \\
\hline 3 & M & 180 & 26 & - & + & 0.13 & 49.3 & 5.05 & 3.43 & 77.3 & B \\
\hline 4 & M & 186 & 29 & - & + & 0.03 & 48.9 & 4.94 & 3.70 & 79.2 & $\mathrm{~B}, \mathrm{C}$ \\
\hline 5 & F & 165 & 29 & - & + & 0.02 & 46.5 & 3.49 & 2.80 & 87.8 & none \\
\hline 6 & F & 170 & 27 & + & + & 0.86 & 63.3 & 3.84 & 3.64 & 105.8 & B \\
\hline 7 & M & 190 & 26 & - & + & 0.09 & 29.0 & 5.57 & 3.95 & 80.1 & B \\
\hline 8 & $\mathrm{M}$ & 175 & 31 & + & + & 0.72 & 28.6 & 5.20 & 3.75 & 90.6 & $\mathrm{~B}, \mathrm{C}$ \\
\hline 9 & $\mathrm{~F}$ & 175 & 25 & + & + & 0.13 & 54.2 & 4.03 & 3.15 & 85.6 & B \\
\hline 10 & M & 181 & 25 & + & + & 1.30 & 37.8 & 6.31 & 5.13 & 112.3 & B \\
\hline 11 & M & 190 & 26 & + & + & 0.12 & 51.1 & 6.62 & 4.83 & 98.0 & B \\
\hline 12 & M & 185 & 38 & - & + & 0.22 & 40.0 & 5.89 & 4.11 & 94.3 & B \\
\hline 13 & M & 175 & 31 & - & + & 0.20 & 34.4 & 4.79 & 3.55 & 85.7 & $\mathrm{~B}, \mathrm{C}$ \\
\hline 14 & M & 185 & 32 & + & + & 0.68 & 49.5 & 4.89 & 4.63 & 102.0 & B \\
\hline 15 & F & 176 & 19 & - & + & 0.53 & 50.2 & 3.91 & 3.80 & 102.2 & none \\
\hline 16 & $\mathrm{~F}$ & 166 & 26 & - & + & 0.34 & 35.5 & 4.66 & 3.23 & 97.9 & $\mathrm{~B}, \mathrm{C}$ \\
\hline 17 & M & 188 & 27 & + & + & 0.26 & 46.0 & 5.28 & 3.62 & 72.6 & B \\
\hline 18 & $\mathrm{~F}$ & 164 & 46 & + & + & 0.02 & 32.6 & 3.65 & 2.95 & 108.5 & B \\
\hline 19 & M & 172 & 34 & - & + & 0.10 & 30.6 & 4.95 & 3.59 & 87.8 & B \\
\hline Mean & & 178 & 30 & & & $0.19^{*}$ & 42.6 & 4.86 & 3.72 & 91.9 & \\
\hline SD & & 8.7 & 6.8 & & & $3.30 *$ & 9.6 & 0.88 & 0.67 & 11.0 & \\
\hline
\end{tabular}

Pt: patient; M: male; F: female; PC20: provocative concentration of methacholine producing a $20 \%$ fall in forced expiratory volume in one second (FEV1); PV20: provocative ventilation rate producing a 20\% fall in FEV1; VC: vital capacity; \% pred: percentage of predicted value; B: inhaled $\beta_{2}$-adrenergic agent used as needed; C: inhaled corticosteroids. *: geometric mean with SD (expressed as a factor).

throughout the study. None of the subjects had an upper or lower respiratory tract infection within 6 weeks of screening. During the study one patient (No. 19) had symptoms of a cold (upper respiratory tract infection). However, these symptoms were not associated with cough or deterioration of lung function parameters.

\section{Study design}

The study was designed as a randomized, placebo-controlled, double-blind, three-way cross-over, single centre within subjects comparative trial. Subjects attended the laboratory on eight occasions. The screening was followed by three 5-day treatment periods with a minimum of 1 week wash out period in between. Zafirlukast and a matching placebo were supplied as film coated tablets for oral use with a dosage of $20 \mathrm{mg}$ or $80 \mathrm{mg}$ b.d. At the beginning of each 5 day treatment period a cold air challenge test was performed at $3 \mathrm{~h}$ following the first dose of treatment. At the end of each 5 day treatment period cold air challenges were done 3, 8, 12, $24 \mathrm{~h}$ following the last morning dose. Subjects attended the clinic at the same time of day $( \pm 2 \mathrm{~h})$ for each visit. In case of low outdoor temperatures (under $10^{\circ} \mathrm{C}$ ) the patients had to take a rest for $60 \mathrm{~min}$ at room temperature after they arrived at the centre.

\section{Lung function measurement}

FEV1 baseline-tests consisted of three forced expiratory manoeuvres carried out according to standard procedures [14] with an electronic spirometer (ZAN Handy; ZAN Co., Oberthulba, Germany). $\beta_{2}$-agonists were withheld for $\geq 6 \mathrm{~h}$ before each spirometry test.

\section{Isocapnic hyperventilation challenge with cold air}

The detailed technique has been described elsewhere [15-17]. Briefly, challenges were conducted with the subject standing and breathing cold, dry air from the hospital's compressed air supply, which was chilled to approximately $-17^{\circ} \mathrm{C}$ by a heat exchanger (RHE-Test; Jaeger Co., Höchberg, Germany), through a two way valve with separated ports for inspiration and expiration. The inspiratory port was attached to an air flow system, which contained a mechanism for indicating the subject's ventilation rate and thus allowing the subject to maintain the desired rate. To determine the provocative ventilation rate required to induce a $10 \%$ fall in FEV 1 (PV10) and a $20 \%$ fall in FEV1 (PV20) each subject breathed for successive 3-min periods at a ventilation rate that started at $20 \mathrm{~L} \cdot \mathrm{min}^{-1}$ and was increased by $10 \mathrm{~L} \cdot \mathrm{min}^{-1}$ at the start of each subsequent period. Cold air challenges were performed when baseline FEV1 was $>70 \%$ of predicted and terminated when a drop in FEV1 of $\geq 20 \%$ from baseline occurred. FEV1 was recorded $30 \mathrm{~s}$ after the end of each ventilation period and after $1.5,3,5$ and $6.5 \mathrm{~min}$ in order to detect the maximum response. The $\mathrm{CO}_{2}$ content of inspired air was adjusted to maintain isocapnic hyperventilation. Subjects were not allowed to perform any exercise prior to their attendance. This included cycling, running or swimming in the morning of the visit and between the different exercise-testings of the day.

\section{Safety assessments}

Safety was determined during each visit by a review of subject's state of health, an interview for subjective symptomatology, routine laboratory tests and recording of adverse events. 


\section{Data evaluation and statistics}

The PV10 and PV20 were calculated by linear interpolation or extrapolation from ventilation-response curves. The first point on the ventilation response curve was assumed to be a value of $0 \%$ at a ventilation rate of $0 \mathrm{~L} \cdot \mathrm{min}^{-1}$. Where possible, linear interpolation was used between adjacent points in order to find the PV10 and PV20. Where a ventilation response curve led to more than one value for PV10 or PV20 the first value was taken. In some cases where interpolation did not yield the PV10 or PV20 extrapolation was used. Linear extrapolation was used to calculate PV10 and PV20 from the last two points on the ventilation curve only where the last point on the ventilation curve was greater than or equal to $5 \%$ and $15 \%$, respectively, fall in FEV1. If the ventilation rate for PV10 calculated by extrapolation was $>80 \mathrm{~L} \cdot \mathrm{min}^{-1}$ the value was set at $85 \mathrm{~L} \cdot \mathrm{min}^{-1}$. The censored values might have introduced some bias into the treatment comparisons but should have introduced less bias than omitting these values from the analysis altogether. Where extrapolation was not possible, a censored value equal to the highest ventilation rate was used.

Because of the large proportion of censored PV20 values a nonparametric analysis by a Friedman's Chi-Squared test was performed using SAS ${ }^{\mathrm{TM}}$ PROC FREQ (SAS ${ }^{\mathrm{TM}}$ Institute Inc., Cary, NC, USA) to test for differences between each zafirlukast treatment and placebo [15]. This test assumes that there are no sequence, period or carryover effects. This assumption was reasonable given by the nonsignificant results of the parametric analyses of the PV10 values. The extent of values for PV10 censored at the highest ventilation rate and at $85 \mathrm{~L} \cdot \mathrm{min}^{-1}$ was $8 \%$ and a parametric analysis by analysis of variance (ANOVA) models was fitted to the data for PV10 using SAS ${ }^{\mathrm{TM}}$ PROC FREQ (SAS ${ }^{\mathrm{TM}}$ Institute Inc.). Separate models were fitted to the data from each time point. The effects of patients (between patients) and the effects of period, treatment and first order carry-over (within patients) were included in the models. The assumptions of the ANOVA were valid for the analysis of PV10 at each time point. First order carry-over, period and treatment sequence were nonsignificant in all models, for PV10 as well as for baseline FEV1. Additionally the maximum fall in FEV1, at a ventilation rate of $30 \mathrm{~L} \cdot \mathrm{min}^{-1}$ was analysed by ANOVA as described for PV10. The mean percentage protection of active treatment over placebo was calculated by: (mean active-mean placebo)/mean placebo $\times 100$. Differences in baseline values of FEV1, before challenge for the three treatment periods were analysed by ANOVA, FEV1, values before and $3 \mathrm{~h}$ after medication were compared by t-test for dependent samples.

According to the study design five hyperventilation challenges were performed for each patient under placebo. Because these five values did not differ statistically from each other, the authors calculated their mean values and the corresponding 95\% upper prediction limits using Student's t-distribution (one tailed) as described before [16]. By these parameters, variability of the response to cold air challenge could be characterized on an individual basis in order to identify responders and nonresponders in this study.

\section{Results}

\section{Premedication lung function and effect on airway tone}

There were no significant differences in predrug baseline FEV1 for the three treatment periods or between first dose and last dose at steady state. Before first dose mean \pm SEM FEV1 was $3.54 \pm 0.15,3.68 \pm 0.15$ and $3.59 \pm 0.13$ for treatment period $80 \mathrm{mg}$ b.i.d. $20 \mathrm{mg}$ b.i.d. zafirlukast and placebo. Before last dose corresponding values were $3.63 \pm$ $0.15,3.65 \pm 0.14$ and $3.61 \pm 0.14$. Three hours after first dose mean $(95 \%$ confidence interval (CI)) increase of FEV1 was $6.2(2.3-10.1) \%$ with zafirlukast $80 \mathrm{mg}$, which was statistically higher as compared to placebo $(\mathrm{p}=0.02)$. The corresponding values for zafirlukast $20 \mathrm{mg}$ were 3.7 (1.1-6.2) $\%$ which was not statistically different from the increase (1.6 (-1.4-4.5) \%) under placebo.

\section{Effect on isocapnic hyperventilation with cold air}

Maximum percentage fall in forced expiratory volume in one second at 3 post first dose at a ventilation rate of 30 $\mathrm{L} \cdot \mathrm{min}^{-1}$. The mean $(95 \% \mathrm{CI})$ fall in FEV1 at a ventilation rate of $30 \mathrm{~L} \cdot \mathrm{min}^{-1}$ was $14.8(11.7-19.1) \%$ in the placebo group compared to $9.1(5.3-13.1)$ and 10.5 (6.7-14.4) in the zafirlukast $80 \mathrm{mg}$ and $20 \mathrm{mg}$ group respectively (fig. 1). Mean percentage protection of $38.4 \%$ for zafirlukast 80 $\mathrm{mg}$ was statistically significant improvement over placebo $(\mathrm{p}=0.016)$. For zafirlukast $20 \mathrm{mg}$ mean protection was $29.1 \%(\mathrm{p}=0.062)$.

$P V 20$ at 3 h post first dose and at steady state. The median values of PV20 $3 \mathrm{~h}$ post first dose and at steady state are presented in table 2 . The individual data are shown in figure 2. Three hours post first dose between zafirlukast $80 \mathrm{mg}$ and placebo the difference was statistically significant $(p=0.004)$. However, the difference between zafirlukast $20 \mathrm{mg}$ and placebo was smaller $(\mathrm{p}=0.064)$. At steady state at all time points the median PV20 of the zafirlukast $80 \mathrm{mg}$ group was consistently $>60 \mathrm{~L} \cdot \mathrm{min}^{-1}$ whilst the median of the placebo group was consistently between $40 \mathrm{~L} \cdot \mathrm{min}^{-1}$ and $50 \mathrm{~L} \cdot \mathrm{min}^{-1}$. The difference between zafirlukast $80 \mathrm{mg}$ and placebo was significant at 8 $\mathrm{h}(\mathrm{p}=0.043)$ and $12 \mathrm{~h}(\mathrm{p}=0.004)$ post last dose. Three

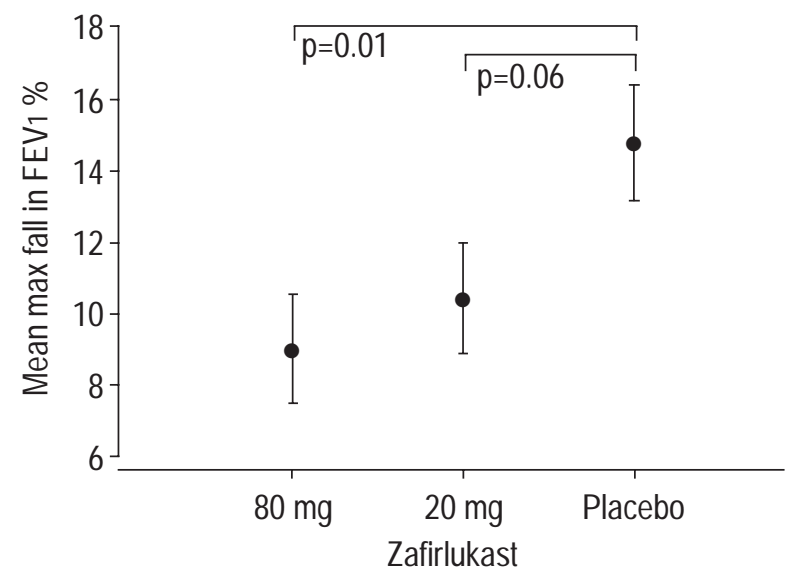

Fig. 1. - Mean maximum fall in forced expiratory volume in one second (FEV1) ( $\left(\right.$ SEM) $3 \mathrm{~h}$ post first dose at ventilation rate $30 \mathrm{~L} \cdot \mathrm{min}^{-1}$ for zafirlukast $20 \mathrm{mg}$ and zafirlukast $80 \mathrm{mg}$ compared to placebo. 
Table 2. - Median values of provocative ventilation rate $\left(\mathrm{L} \cdot \mathrm{min}^{-1}\right)$ to reduce forced expiratory volume in one second by $20 \%$ and range after first dose and $3,8,12,24 \mathrm{~h}$ after last dose for $80 \mathrm{mg}$ and $20 \mathrm{mg}$ zafirlukast

\begin{tabular}{lccc}
\hline $\begin{array}{l}\text { Timing of cold } \\
\text { air challenge }\end{array}$ & $\begin{array}{c}\text { Zafirlukast } \\
80 \mathrm{mg} \text { b.d. }\end{array}$ & $\begin{array}{c}\text { Zafirlukast } \\
20 \mathrm{mg} \text { b.d. }\end{array}$ & Placebo \\
\hline $3 \mathrm{~h}$ post & $69.1^{*}$ & $59.9^{\dagger}$ & 40.0 \\
first dose & $(15.7-85.0)$ & $(21.0-85.0)$ & $(15.5-85.0)$ \\
$3 \mathrm{~h}$ post & $69.0^{\dagger}$ & $65.3^{\dagger}$ & 48.7 \\
last dose & $(27.0-85.0)$ & $(21.0-85.0)$ & $(22.4-85.0)$ \\
$8 \mathrm{~h}$ post & $71.8^{*}$ & $55.3^{*}$ & 46.5 \\
last dose & $(21.0-85.0)$ & $(28.4-85.0)$ & $(17.2-85.0)$ \\
12 h post & $63.8^{*}$ & 45.3 & 47.6 \\
last dose & $(24.2-85.0)$ & $(13.9-85.0)$ & $(18.9-85.0)$ \\
24 h post & 65.0 & 55.3 & 49.2 \\
last dose & $(21.1-85.0)$ & $(22.8-85.0)$ & $(14.2-85.0)$ \\
\hline
\end{tabular}

p-value versus placebo: *: $\mathrm{p}<0.05 ;^{\dagger}: \mathrm{p} \leq 0.10$.

hours post last dose the effect of $80 \mathrm{mg}$ was not statistically significant $(\mathrm{p}=0.086)$. The difference between zafirlukast $20 \mathrm{mg}$ and placebo was statistically significant only at $8 \mathrm{~h}$ post last dose $(\mathrm{p}=0.024)$.

PV10 at 3 h post first dose and at steady state. Mean values and $95 \%$ confidence intervals for PV10 are given in table 3 and individual data for three patients are shown in figure 3. Zafirlukast $80 \mathrm{mg}$ showed $3 \mathrm{~h}$ post first dose a mean protection of $61.5 \%(\mathrm{p}=0.006)$ as compared to placebo and $3,8,12$ and $24 \mathrm{~h}$ post last dose $20.6 \%(\mathrm{p}=0.103)$, $25.3 \%(\mathrm{p}=0.089), 44.5 \%(\mathrm{p}=0.011)$ and $14.6 \%(\mathrm{~ns})$. For zafirlukast $20 \mathrm{mg}$ protection was weaker at all time points as compared to zafirlukast $80 \mathrm{mg}$, except at $3 \mathrm{~h}$ post last dose (protection 21.5\%, $\mathrm{p}=0.091$ ).

During the study, altogether five challenges in three subjects could not be performed due to poor baseline values of FEV1 (three times placebo (subject No. 17), two times zafirlukast $20 \mathrm{mg} 24 \mathrm{~h}$ (subjects no. 8 and no. 9)).

\section{Adverse events}

Adverse events were reported by fewer patients after zafirlukast $80 \mathrm{mg}$ (eight patients; 42\%) compared to zafir-

Table 3. - Mean values of provocative ventilation rate $\left(\mathrm{L} \cdot \mathrm{min}^{-1}\right)$ to reduce forced expiratory volume in one second by $10 \%$ and $(95 \%$ confidence intervals) after first dose and $3,8,12,24 \mathrm{~h}$ after last dose for $80 \mathrm{mg}$ and $20 \mathrm{mg}$ zafirlukast

\begin{tabular}{lccc}
\hline $\begin{array}{l}\text { Timing of cold } \\
\text { air challenge }\end{array}$ & $\begin{array}{c}\text { Zafirlukast } \\
80 \mathrm{mg} b . d .\end{array}$ & $\begin{array}{c}\text { Zafirlukast } \\
20 \mathrm{mg} b . d .\end{array}$ & Placebo \\
\hline 3 h post & 39.9 & 32.9 & 24.7 \\
first dose & $(30.6-49.2)^{*}$ & $(25.1-40.7)$ & $(18.6-30.8)$ \\
$3 \mathrm{~h}$ post & 39.8 & 40.1 & 33.0 \\
last dose & $(30.7-49.0)^{\dagger}$ & $(32.6-47.5)^{\dagger}$ & $(25.6-40.4)$ \\
$8 \mathrm{~h}$ post & 41.6 & 37.2 & 33.2 \\
last dose & $(29.1-54.0)$ & $(27.2-47.2)$ & $(23.1-43.3)$ \\
$12 \mathrm{~h} \mathrm{post}$ & 40.6 & 27.8 & 28.1 \\
last dose & $(31.3-49.9)^{*}$ & $(21.1-34.5)$ & $(20.5-35.7)$ \\
24 h post & 36.1 & 28.1 & 31.5 \\
last dose & $(26.0-46.3)$ & $(23.0-33.2)$ & $(23.3-39.7)$ \\
\hline
\end{tabular}

p-value versus placebo:*: $\mathrm{p}<0.05 ;{ }^{\dagger}: \mathrm{p} 0.10$. lukast $20 \mathrm{mg}$ (11 patients; 58\%) or placebo (11 patients; $58 \%$ ). Headache was reported most frequently. However, incidence was similar across all groups. No patients had adverse events which led to withdrawal or were reported as serious. There were no treatment related differences in the laboratory parameters.

\section{Discussion}

Antileukotrienes are effective in attenuation of exercise and cold-air induced bronchoconstriction [4-10]. This beneficial effect has been demonstrated both for synthesisinhibitors and cysteinyl-leukotriene $(\text { cysLT) })_{1}$-receptor antagonists. In this study the authors could demonstrate that zafirlukast offers significant protection against bronchoconstriction induced by isocapnic hyperventilation of cold air $3 \mathrm{~h}$ after ingestion of $20 \mathrm{mg}$ and $80 \mathrm{mg}$, and that 80 $\mathrm{mg}$ was significantly more effective than $20 \mathrm{mg}$. There was a small acute effect on airway tone after first dose, which was greater with zafirlukast $80 \mathrm{mg}$. Results from other studies suggest that the effect on airway tone depends on the degree of pre-existing bronchoconstriction. LiU et al. [20] reported in their results from a 6 month trial with zileuton a mean increase in FEV1, of $38 \%$ in the patients with FEV $1<50 \%$ pred compared to $15 \%$ for the whole group. As the asthmatics from the current study had a mean FEV1, of $92 \%$ pred a marked bronchodilator effect was not likely to occur.

After repeated dosages over 5 days the authors found $3 \mathrm{~h}$ after the last dose a less pronounced effect which did not reach statistical significance. Though these observations were statistically stable within the group of 19 asthmatics, individual differences were remarkable, indicating an individual factor determining the airway response to the cysLT $\mathrm{T}_{1}$ receptor antagonist zafirlukast. The interpretation of the findings needs discussion of various aspects, as follows.

The authors used the method of isocapnic hyperventilation of cold air to assess airway responsiveness. Airway response following exercise and hyperventilation provides a similar degree of airway obstruction provided ventilation rate, temperature and water content of inspired air are matched [21]. This method has been used by the authors $[15,16]$ and other groups in several different studies $[17$, $22,23]$. Isocapnic hyperventilation as used in this study offers the advantage of constructing a dose-response curve rather than measuring airflow obstruction after a single test. This offers the possibility of calculating provocative ventilation (PV) rates necessary to decrease e.g. FEV1 by 10 or $20 \%$ from baseline similar to those methods used for assessment of the response to bronchoconstrictor agents like histamine or methacholine. In addition reproducibility of PV-values is acceptable $[15,24]$. Therefore, similar to other groups, the authors used this technique to simulate exercise-induced bronchoconstriction. The authors analysed the data in terms of both PV10 and PV20 in order to circumvent the difficulties associated with both parameters. The analysis of PV20 was hampered by censored values, whereas that of PV10 was affected by the higher variability of this parameter. For example, subject No. 11 showed a variation from $8-60 \mathrm{~L} \cdot \mathrm{min}^{-1}$, in contrast to, e.g., subject No. 7 whose PV10 varied between $21-26 \mathrm{~L} \cdot \mathrm{min}^{-1}$ on five occasions under placebo (fig. 3). Despite these differences, the results were similar for both parameters. 


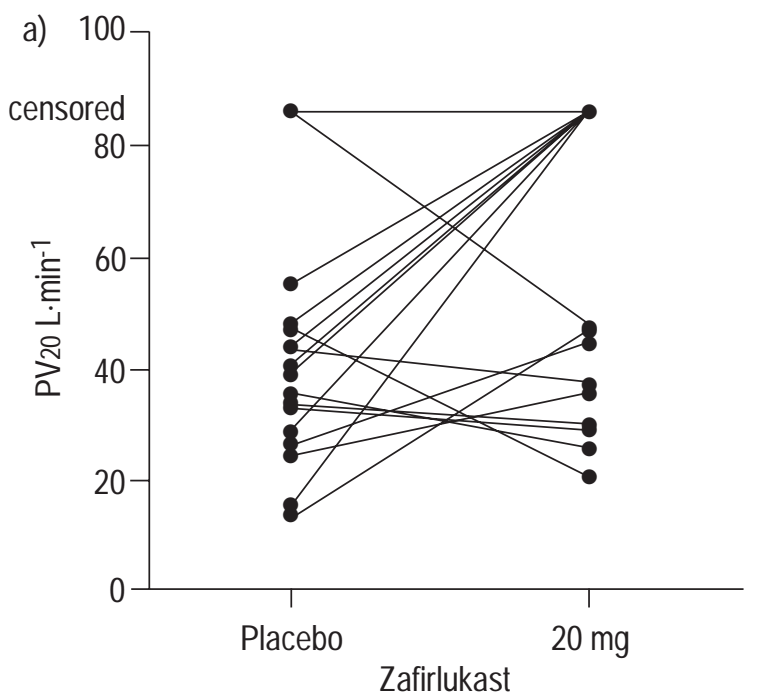

b)

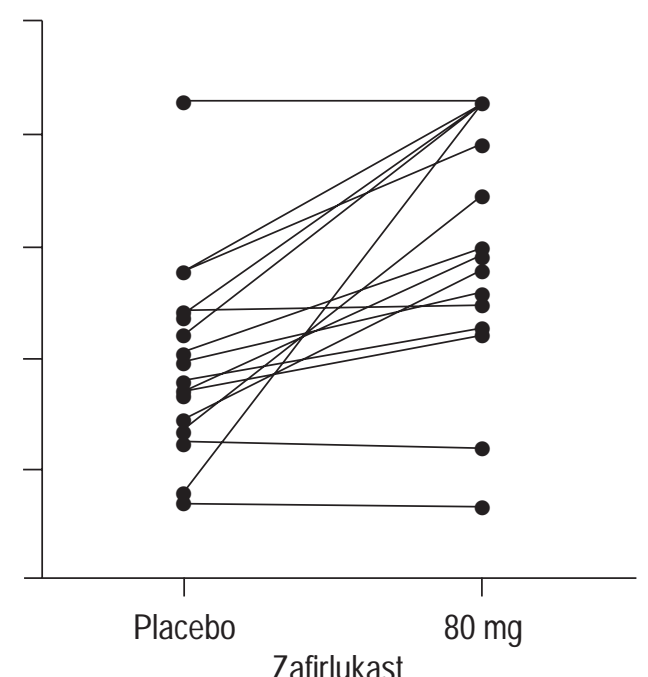

Fig. 2. - Provocative ventilation rate to reduce forced expiratory volume in one second by $20 \%$ (PV20) 3 h after single medication: a) 20 mg zafirlukast compared to placebo; b) $80 \mathrm{mg}$ zafirlukast compared to placebo. If PV20 could not be determined by extrapolation a censored value of $85 \mathrm{~L}^{-m_{i n}}{ }^{-1}$ (see Data evaluation and statistics section) was assigned. Data shown are for individual patients. Data for subject no. 17 are not shown due to missing placebo value.

The data assessed $3 \mathrm{~h}$ after a single dose of 20 and $80 \mathrm{mg}$ zafirlukast are compatible with data from the literature in terms of frequency and magnitude of protection [4-6]. These studies have also demonstrated a variable protection with almost complete, down to no protection in some subjects. The data can be compared to data of two different studies reported in the literature using the same methodology, which reported inconsistent results $[11,12]$. However these data are only available in abstract form and the time points of cold-air challenge differ between the studies. In 24 patients with asthma ISRAEL et al. [11] did not find any significant effect on cold-air induced bronchoconstriction $2 \mathrm{~h}$ after single treatment with 20 or $40 \mathrm{mg}$ zafirlukast. Eight hours after single dose they saw an increase of $29 \%$ and $32 \%$ of the amount of cold air required to decrease FEV 1 by $10 \%$ for treatment with 20 and $40 \mathrm{mg}$ zafirlukast compared to placebo without any significant difference between the doses. However, Boulet et al. [12] observed no effect 30 min and $4 \mathrm{~h}$ after a single dose of $80 \mathrm{mg}$ zafirlukast in 10 asthmatic subjects. After $24 \mathrm{~h}$ there was a small but stat- istically significant effect of an increase of $17 \%$ for the ventilation rate required to decrease the FEV1 by $20 \%$.

Repeated dosing of zafirlukast results in a steady state condition within 4 days of treatment [25]. Therefore values of PV20 $3 \mathrm{~h}$ after repeated dosing should closely mimic long-term treatment effects. Comparing the $3 \mathrm{~h}$ effect after the first dose with chronic dosing permits an idea of tolerance to be obtained. After repeated dosing the protection was decreased in the subjects, suggesting that there might be some tolerance. Similar observations have recently reported by ÁDELROTH et al. [26], who found that the protection afforded by $10 \mathrm{mg}$ cinalukast was lost after 7 days of treatment but persisted with $50 \mathrm{mg}$ and $200 \mathrm{mg}$ doses. As this group observed the attenuated protection only at low doses the current observation may be overcome using higher doses of zafirlukast. On the other hand, $20 \mathrm{mg} \mathrm{b.d}$. provided significant protection $8 \mathrm{~h}$ and $80 \mathrm{mg} 8$ and $12 \mathrm{~h}$ after last dose; the effect at $3 \mathrm{~h}$ was not statistically significant ( $\mathrm{p}=0.09$ ). It might be possible, that the timepoint of effectiveness changes with chronic
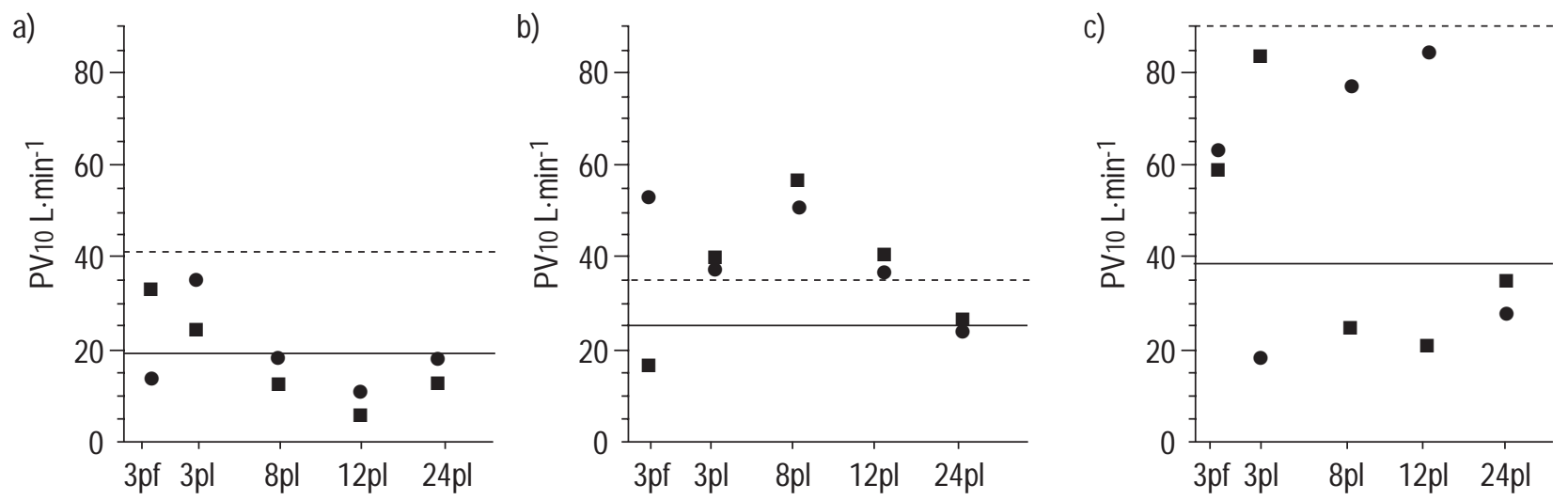

Fig. 3. - Individual values of provocative ventilation rate to reduce forced expiratory volume in one second by $10 \%$ (PV10) $3 \mathrm{~h}$ post first ( $3 \mathrm{pf}$ ) and 3 , 8 , 12 and $24 \mathrm{~h}$ post last (pl) medication with $20 \mathrm{mg}(\boldsymbol{\square})$ zafirlukast or $80 \mathrm{mg}$ b.i.d. zafirlukast (O). For each patient the solid horizontal line indicates the mean value of PV10 calculated from five placebo values. The dashed horizontal line shows a confidence band in terms of the $95 \%$ upper prediction limit (all starting at zero). An example of each, a) a nonresponder (No. 1), b) a responder (No. 19) and c) a subject with high variability of PV10 (No. 11) is given. 
treatment. Hofstra et al. [27] recently reported significant protection against exercise induced asthma after 2 weeks treatment with $20 \mathrm{mg}$ and $80 \mathrm{mg} \mathrm{b.d}$. zafirlukast 4 and $8 \mathrm{~h}$ after the final dose, however they did not assess the effect after the first dose in this group of patients. There was no evidence from the current data that either dose of zafirlukast continued to provide protection against cold air challenge $24 \mathrm{~h}$ after the last dose.

Inspection of the individual values indicated that not all patients were protected against hyperventilation of cold air after treatment with zafirlukast (figs. 2 and 3). For example, figure 3 illustrates that subject No. 1 might be identified as a nonresponder and subject No. 19 as a responder. In contrast, subject No. 11 showed such a high degree of variability under placebo conditions that it was impossible to draw any conclusion about the potential effects of zafirlukast. In previous studies with cysLT ${ }_{1}$-receptor antagonists and 5-lipoxygenase inhibitors it has been shown that $\sim 30-40 \%$ of the subjects did not show any beneficial effect on protection against bronchoconstriction induced by exercise or cold air $[4,5]$. In a more recent study FISCHER et al. [28] analysed the protective effect of a 5-lipoxygenase inhibitor against cold air challenge. The individual data, which they presented, also indicated responders as well as nonresponders. Whether this heterogeneity is peculiar for antileukotrienes or will also be found with other antiasthmatic treatment has not been directly shown by a comparison of different drugs in the same subject. However, from a clinical point-of-view it is particularly important to realize that zafirlukast may offer in some subjects pronounced and in others no effect against naturally occurring stimuli. The response seems to be independent of PC20 methacholine, the baseline lung function or the current therapy. It is possible that the protective effect can be predicted from cysLT-levels in biological fluids like urine, bronchoalveolar lavage (BAL) fluid or sputum. However, few studies have correlated leukotriene-levels with clinical data. CysLT have been demonstrated to be increased after allergen challenge in BAL [29, 30]. Increased urinary leukotriene $\mathrm{E}_{4}$ levels have been found during acute episodes of asthma [31] and in patients with nocturnal asthma [32]. There are contradictory data in the literature about cysLT-levels in BAL fluid after exercise or cold-air induced bronchoconstriction. Different investigators have not found increased cysLT-levels in urine or BAL after exercise in adults [33-35] whereas other investigators have reported increased urinary leukotriene $\mathrm{E}_{4}$ levels in asthmatic children after exer-cise and in adults [36]. In accordance with this, PLiss et al. [1] described increased cysLT-levels in BAL fluid after hyperventilation. There are only very few and preliminary data about cysLTlevels in sputum samples from asthmatics [36].

The current data provide further evidence that there is a large interindividual variability in the protective effect of the cysteinyl-leukotriene ${ }_{1}$-receptor antagonists or 5-lipoxygenase synthase inhibitors against cold-air or exercise induced bronchoconstriction and there is to date no predictive parameter available for responders and nonresponders.

\footnotetext{
Acknowledgements. The authors thank S. Koschyk, M. Mücke and P. Speckin for excellent technical assistance.
}

\section{References}

1. Pliss LB, Ingenito EP, Ingram RH, Pichurko B. Assessment of bronchoalveolar cell and mediator response to isocapnic hyperpnea in asthma. Am Rev Respir Dis 1990; 142: 73-78.

2. Togias AG, Naclerio R, Peters S, et al. Local generation of sulfidopeptide leukotrienes upon nasal provocation with cold dry air. Am Rev Respir Dis 1986; 133: 11331137.

3. Kikawa Y, Miyanomae T, Inoue Y, et al. Urinary leukotriene $\mathrm{E}_{4}$ after exercise challenge in children with asthma. J Allergy Clin Immunol 1992; 89: 1111-1119.

4. Finnerty JP, Wood-Baker R, Thomson H, Holgate ST. Role of leukotrienes in exercise-induced asthma. Inhibitory effect of ICI 204,219, a potent leukotriene $\mathrm{D}_{4}$ antagonist. Am Rev Respir Dis 1992; 145: 746-749.

5. Makker HK, Lau LC, Thomson HW, Binks SM, Holgate ST. The protective effect of inhaled leukotriene $\mathrm{D}_{4^{-}}$ receptor antagonist ICI 204,219 against exercise-induced asthma. Am Rev Respir Dis 1993; 147: 1413-1418.

6. Manning PJ, Watson RM, Margolskee DJ, Williams VC, Schwartz JI, O'Bryne PM. Inhibition of exercise-induced bronchoconstriction by $\mathrm{MK}-571$, a leukotriene $\mathrm{D}_{4}$-receptor antagonist. $N$ Engl J Med 1990; 323: 1736-1739.

7. Lehnigk B, Rabe KF, Dent G, Herst RS, Carpentier PJ, Magnussen H. Effect of a 5-lipoxygenase inhibitor, ABT761 , on exercise-induced bronchoconstriction and urinary $\mathrm{LTE}_{4}$ levels in asthmatic patients. Eur Respir $J$ 1998; 11: 617-623.

8. Robuschi M, Riva E, Fuccella LM, et al. Prevention of exercise-induced bronchoconstriction by a new leukotriene antagonist (SK\&F) 104,353. Am Rev Respir Dis 1992; 145: 1285-1288.

9. Israel E, Juniper EF, Callaghan JT, et al. Effect of a leukotriene antagonist, LY 171883, on cold air-induced bronchoconstriction in asthmatics. Am Rev Respir Dis 1989; 140: 1348-1353.

10. Israel E, Dermarkarian R, Rosenberg M, et al. The effects of a 5-lipoxygenase inhibitor on asthma induced by cold, dry air. N Engl J Med 1990; 323: 1740-1744.

11. Israel E, Lavins BJ, Miller CJ, Cohn J. Effect of zafirlukast (20 and $40 \mathrm{mg}$ ) on cold-air-induced bronchoconstriction in patients with bronchial asthma. Eur Resp $J$ 1996; 9 (Suppl 23): S51.

12. Boulet LP, Bai TR, Miller CJ, et al. Effect of zafirlukast on cold-air-induced bronchoconstriction in patients with asthma. Eur Respir J 1996; 9 (Suppl 23): S273.

13. Jorres RA, Nowak D, Kirsten D, Gronke L, Magnussen H. A short protocol for methacholine provocation testing adapted to the Rosenthal-Chai dosimeter technique. Chest 1997; 111: 866-869.

14. Quanjer PH, Tammeling GJ, Cotes JE, Pedersen OF, Peslin R, Yernault JC. Lung volumes and forced ventilatory flows. Report Working Party Standardization of Lung Function Tests, European Community for Steel and Coal. Official Statement of the European Respiratory Society. Eur Respir J Suppl 1993; 16: 5-40.

15. Nowak D, Kuziek G, Joerres R, Magnussen H. Comparison of refractoriness after exercise and hyperventilation-induced asthma. Lung 1991; 169: 57-67.

16. Nowak D, Joerres R, Rabe KF, Luethke M, Wiessmann J, Magnussen H. Salmeterol protects against hyperventilation-induced bronchoconstriction over 12 hours. Eur J Clin Pharmacol 1992; 43: 591-595.

17. Malo JL, Cartier A, L'Archeveque J, Ghezzo H, Martin RR. Cold air inhalation has a cumulative bronchospastic 
effect when inhaled in consecutive doses for progressively increasing degrees of ventilation. Am Rev Respir Dis 1986; 134: 990-993.

18. Runyon RP. Nonparametric statistics: a contemporary approach. Reading, MA, USA, Addison-Wesley Publishing Company 1977; 110-112.

19. Magnussen H, Reuss G, Jörres R, Aurich R. Duration of the effect of a single dose of azelastine on histamin-induced bronchoconstriction. J Allergy Clin Immunol 1989; 83: 467-471.

20. Liu MC, Dubé LM, Lancaster J and the Zileuton study group. Acute and chronic effects of a 5-lipoxygenase inhibitor in asthma: a 6 month randomized multicenter trial. J Allergy Clin Immunol 1996; 98: 859-871.

21. Deal EC Jr., McFadden ER Jr., Ingram RH Jr., Strauss RH, Jaeger JJ. Role of respiratory heat exchange in production of exercise-induced asthma. J Appl Physiol 1979; 46: 467-475.

22. Cartier A, Ghezzo H, L'Archeveque J, Trudeau C, Malo JL. Duration and magnitude of action of 50 and $100 \mu \mathrm{g}$ of inhaled salmeterol in protecting against bronchoconstriction induced by hyperventilation of dry cold air in subjects with asthma. J Allergy Clin Immunol 1993; 92: 488-492.

23. Malo JL, Ghezzo H, Trudeau C, L'Archeveque J, Cartier A. Salmeterol, a new inhaled beta 2-adrenergic agonist, has a longer blocking effect than albuterol on hyperventilation-induced bronchoconstriction. J Allergy Clin Immunol 1992; 89: 567-574.

24. Tessier P, Cartier A, L'Archeveque J, Ghezzo H, Martin RR, Malo JL. Within- and between-day reproducibility of isocapnic cold air challenges in subjects with asthma. $J$ Allergy Clin Immunol 1986; 78: 379-387.

25. Accolate Product Monograph. March 1996, Macclesfield, England, Zeneca Pharmacouticals.

26. Ädelroth E, Inman MD, Summers E, Pace D, Modi M, O'Byrne PM. Prolonged protection against exerciseinduced bronchoconstriction by the leukotriene $\mathrm{D}_{4^{-}}$ receptor antagonist cinalukast. J Allergy Clin Immunol 1997; 99: 210-215.
27. Hofstra WB, Sterk PJ, Neijens HJ, van der Weij AM, van Zoest JGCM, Duiverman EJ. Two weeks treatment with zafirlukast (Accolate ${ }^{\mathrm{TM}}$ ), sodium cromoglycate or placebo on exercise-induced bronchoconstriction in asthmatic adolescents. Am J Respir Crit Care Med 1997; 155: A665.

28. Fischer AR, Rosenberg MA, Roth M, Loper M, Jungerwirth S, Israel E. Effect of a novel 5- lipoxygenase activating protein inhibitor, BAYx 1005, on asthma induced by cold air. Thorax 1997; 52: 1074-1077.

29. Wenzel SE, Larsen GL, Johnston K, Voelkel NF, Westcott JY. Elevated levels of leukotriene $\mathrm{C}_{4}$ in bronchoalveolar lavage fluid from atopic asthmatics after endobronchial allergen challenge. Am Rev Respir Dis 1990, 142: 112119.

30. Wenzel SE, Westcott JY, Larsen GL. Bronchoalveolar lavage fluid mediator levels 5 minutes after allergen challenge in atopic subjects with asthma: relationship to the development of late asthmatic responses. J Allergy Clin Immunol 1991; 87: 540-548.

31. Drazen JM, O'Brien J, Sparrow D et al. Recovery of leukotriene $\mathrm{E}_{4}$ from the urine of patients with airways obstruction. Am Rev Respir Dis 1992; 146: 104-108.

32. Bellia V, Cuttitta G, Mirabella A, et al. Urinary leukotriene $\mathrm{E}_{4}$ as a marker of nocturnal asthma. Am Rev Respir Dis 1992; 145: A16.

33. Taylor IK, Willings R, Taylor GW, Fuller RW. Urinary leukotriene $\mathrm{E}_{4}$ excretion in exercise induced asthma. $J$ Appl Physiol 1992; 73: 743-748.

34. Smith CM, Christie PE, Hawksworth RJ, Thien F, Lee $\mathrm{TH}$. Urinary leukotriene $\mathrm{E}_{4}$ levels after allergen and exercise challenge in bronchial asthma. Am Rev Respir Dis 1991; 144: 1411-1413.

35. Broide DH, Eisman S, Ramsdell JW, Ferguson P, Schwartz LB, Wasserman SI. Airway levels of mast cell-derived mediators in exercise-induced asthma. $\mathrm{Am}$ Rev Respir Dis 1990; 141: 563-568.

36. Way W, Sasagawa M, Takemoto A, et al. Sputum leukotrienes in chronic airway diseases and bronchial asthma attacks. Nippon Kyobu Shikkan Gakkai Zasshi 1992; 30: 1695-1703. 